ARTICLE

https://doi.org/10.1038/s41467-021-22035-0

\title{
Experimental evidence for hydrogen incorporation into Earth's core
}

 \\ Yasuo Ohishi ${ }^{4}$ \& Hisayoshi Yurimoto (10) 2,5
}

Hydrogen is one of the possible alloying elements in the Earth's core, but its siderophile (ironloving) nature is debated. Here we experimentally examined the partitioning of hydrogen between molten iron and silicate melt at 30-60 gigapascals and 3100-4600 kelvin. We find that hydrogen has a metal/silicate partition coefficient $D_{H} \geq 29$ and is therefore strongly siderophile at conditions of core formation. Unless water was delivered only in the final stage of accretion, core formation scenarios suggest that $0.3-0.6 \mathrm{wt} \% \mathrm{H}$ was incorporated into the core, leaving a relatively small residual $\mathrm{H}_{2} \mathrm{O}$ concentration in silicates. This amount of $\mathrm{H}$ explains $30-60 \%$ of the density deficit and sound velocity excess of the outer core relative to pure iron. Our results also suggest that hydrogen may be an important constituent in the metallic cores of any terrestrial planet or moon having a mass in excess of $\sim 10 \%$ of the Earth.

\footnotetext{
${ }^{1}$ Department of Earth and Planetary Science, The University of Tokyo, Bunkyo, Tokyo 113-0033, Japan. ${ }^{2}$ Creative Research Institution (CRIS), Hokkaido University, Sapporo, Hokkaido 001-0021, Japan. ${ }^{3}$ Earth-Life Science Institute, Tokyo Institute of Technology, Meguro, Tokyo 152-8550, Japan. ${ }^{4}$ Japan Synchrotron Radiation Research Institute, Sayo, Hyogo 679-5198, Japan. ${ }^{5}$ Department of Natural History Sciences, Hokkaido University, Sapporo, Hokkaido

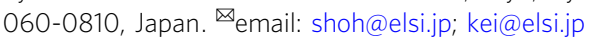


E xisting Earth's core formation models constrained by partitioning of moderately siderophile elements suggest that metals equilibrated with molten silicates in a deep "magma ocean" under high-pressure and -temperature $(P-T)$ conditions up to about $60 \mathrm{GPa}$ and $4000 \mathrm{~K}^{1-6}$ (Supplementary Fig. 1). While hydrogen is one of the plausible impurity elements in the iron-rich core $^{7}$, its metal-silicate partitioning under such conditions has been controversial in both experiments $^{8-12}$ and theory ${ }^{13-15}$. Previous experimental studies on the metal-silicate partitioning of hydrogen were performed below $20 \mathrm{GPa}$ using molten ${ }^{8,11,12}$ and solid ${ }^{9,10}$ silicates. While hydrogen has been found to be strongly siderophile under high pressure $^{8-10}$, these results were challenged by more recent experiments ${ }^{11,12}$. These later studies ${ }^{11,12}$ found low hydrogen concentrations in iron, which may be attributed to the fact that they conducted carbon-saturated experiments, leading to carbon enrichment in metal that may hinder hydrogen incorporation. It is also possible that hydrogen escaped from their samples prior to measurements performed after they were decompressed and recovered at ambient conditions, where $\mathrm{FeH}_{X}$ is known to decompose ${ }^{10}$ into bcc $\mathrm{Fe}$ and molecular $\mathrm{H}_{2}$. The equilibrium hydrogen solubility in bcc $\mathrm{Fe}$ at an $\mathrm{H}_{2}$ pressure of 1 bar is limited to ${ }^{16} X<10^{-5}$. Loss of hydrogen from iron samples during decompression has been demonstrated in previous neutron diffraction ${ }^{10}$ as well as our new X-ray diffraction (XRD) measurements (Supplementary Fig. 2).

Here, we report experiments to constrain the partitioning of hydrogen between molten iron and silicate melt at high $P-T$ to $60 \mathrm{GPa}$. The results demonstrate the strongly siderophile nature of hydrogen under conditions where metals segregated from silicates during Earth's core formation, suggesting that hydrogen is an important light element in the core. In addition, hydrogen may be a major impurity element in the metallic cores of other terrestrial planets and moons whose masses are more than $10 \%$ of that of the Earth.

\section{Results and discussion}

Metal-silicate partitioning of hydrogen. We carried out metal-silicate partitioning experiments at $30-60 \mathrm{GPa}$ and $3100-4600 \mathrm{~K}$ in a diamond-anvil cell (DAC) (Supplementary Table 1 and Supplementary Fig. 3) and found 5300 to 26,000 ppm H (by weight) in metal at high pressure (before decompression), on the basis of the phase proportion and lattice volume of $\mathrm{FeH}_{X}$ and $\varepsilon$ - $\mathrm{FeOOH}$ that formed from liquid iron upon temperature quenching under sustained confining pressure (Fig. 1a) (see "Methods"). Note that liquid iron was likely to have quenched fully to crystals and subsequent thermal annealing in a separate experiment had a negligible effect upon hydrogen concentrations (only $6 \%$ difference) ${ }^{17}$. On the other hand, we obtained 90-470 ppm $\mathrm{H}$ (present as $\mathrm{H}_{2} \mathrm{O}$ ) in quenched silicate melts by measuring recovered samples using a high-resolution imaging technique coupled with secondary ion mass spectrometry (SIMS) (Fig. 1b), which enabled quantitative compositional analysis of a small DAC sample (see "Methods"). In $D_{\mathrm{H}}^{\text {metal/silicate }}$ we found ranges from 29 to 57 by weight (Fig. 2a), indicating that hydrogen is siderophile at these $P-T$ conditions.

The metal-silicate partitioning of hydrogen can be expressed as a chemical reaction,

$$
\mathrm{HO}_{0.5}^{\text {silicate melt }}+\frac{1}{2} \mathrm{Fe}^{\text {metal }}=\mathrm{H}^{\text {metal }}+\frac{1}{2} \mathrm{FeO}^{\text {silicate melt }}
$$

The exchange coefficient $K_{\mathrm{D}}$ is parameterized as a function of $P(\mathrm{GPa})$ and $T(\mathrm{~K})$ with regression constants $a$,
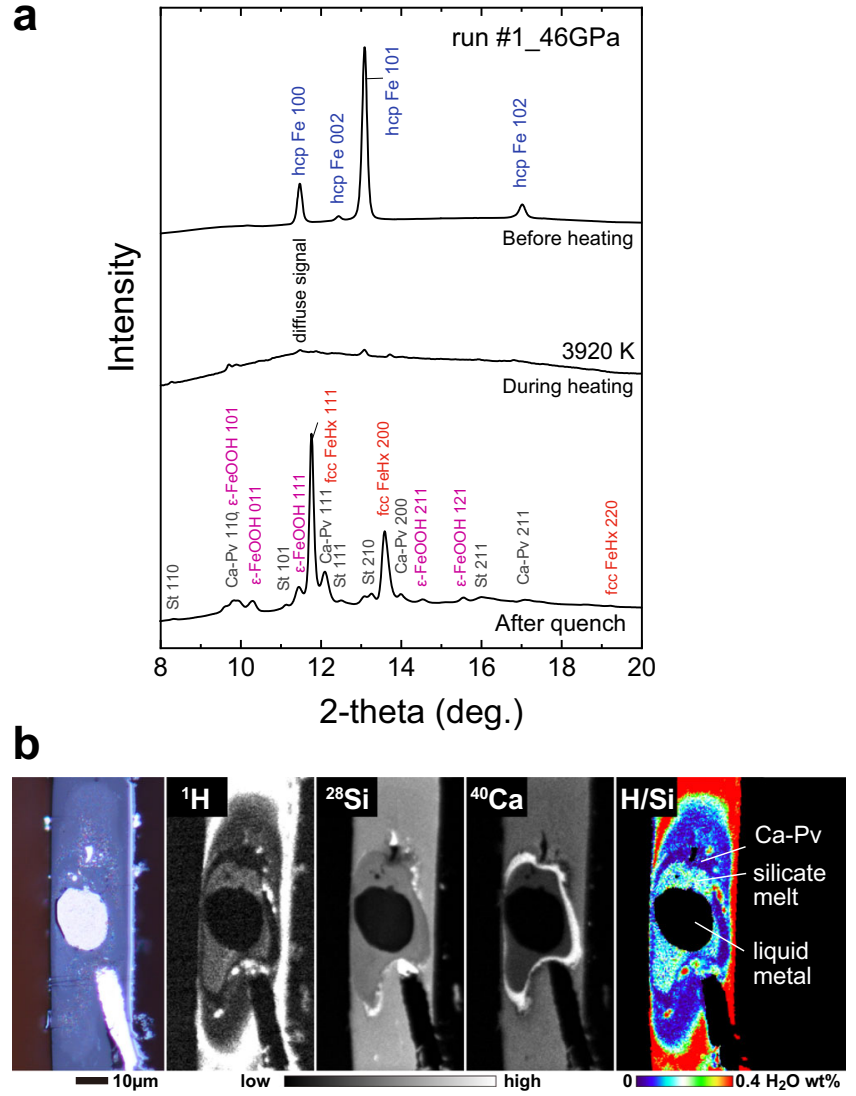

Fig. 1 Analyses of hydrogen in metal and silicate. a XRD patterns collected before/during/after heating to $3920 \mathrm{~K}$ at $46 \mathrm{GPa}$ in run \#1. Both iron and silicate were molten at the center of a laser-heated spot during heating. Hydrogen concentration in liquid metal was obtained from those in fcc $\mathrm{FeH}_{X}$ and $\varepsilon-\mathrm{FeOOH}$. b Photomicrograph (left), secondary ion images for ${ }^{1} \mathrm{H}^{+},{ }^{28} \mathrm{Si}^{+}$, and ${ }^{40} \mathrm{Ca}+$ (middle), and a distribution map of water (right). Note the absence of hydrogen in metal because it escaped from iron upon releasing pressure. Hydrogen (water) content in quenched silicate melt was obtained with $\pm 2 \%$ to $\pm 7 \%$ relative uncertainty.

$b$, and $c$ (Fig. 2b),

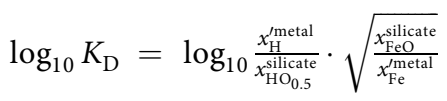

$$
\begin{aligned}
& =\log _{10} \frac{x_{\mathrm{H}}^{\text {metal }}}{x_{\mathrm{HO} \text { ilicate }}^{\text {sit }}}+\frac{1}{4} \Delta \mathrm{IW} \\
& =a+\frac{b}{T}+c \cdot \frac{P}{T}
\end{aligned}
$$

where $x$ represents molar fraction (see "Methods" for $x^{\prime}$ ) and the effects of $\mathrm{Si}, \mathrm{O}$, and $\mathrm{C}$ are not parameterized explicitly. Oxygen fugacity $f_{2}$ relative to the iron-wüstite (IW) buffer is approximated as $\Delta \mathrm{IW} \approx 2 \log _{10}\left(x_{\mathrm{FeO}}^{\text {silicate }} / x_{\mathrm{Fe}}^{\prime \text { metal }}\right)$ following previous studies ${ }^{2,3}$. Least-squares fitting to our data yields $a=$ 2.42 (18), $b=-2892$ (433), and $c=-32.0$ (87).

Incorporation of hydrogen during core formation. The partition coefficient only constrains the relative proportion of hydrogen in metal and silicates at equilibrium. In order to estimate the amount of hydrogen that entered metal during core formation, it is necessary to specify the concentration of $\mathrm{H}_{2} \mathrm{O}$ in the silicate magma ocean (MO) with which it equilibrated. If we assume that negligible hydrogen is able to enter the core after formation, and that hydrogen was continuously delivered to the proto-Earth during accretion (as opposed to late), then plausible 

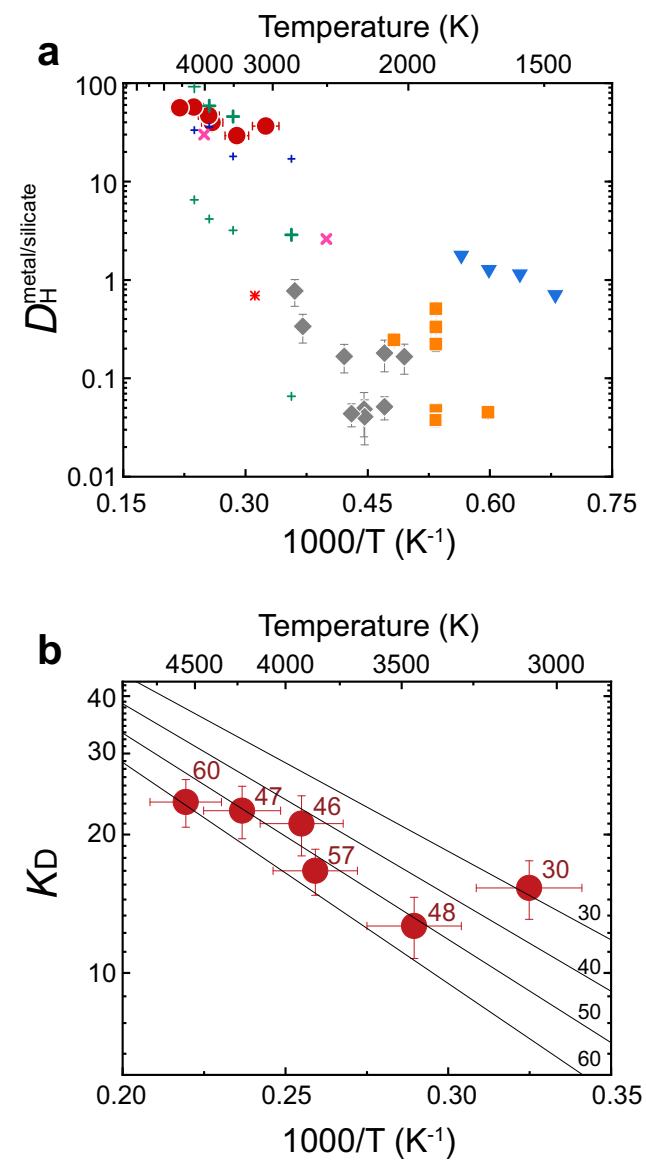

Fig. 2 Metal-silicate partitioning of hydrogen. a Partition coefficient $D$ (by weight) for hydrogen as a function of reciprocal temperature. The present experiments (red circles) show that hydrogen is strongly siderophile under conditions of Earth's core formation. Recent experimental studies (gray diamonds ${ }^{11}$, orange squares ${ }^{12}$ ) reported $D$ values lower by one to three orders of magnitude than the present results, which is likely attributed to hydrogen loss from metals during decompression. Pioneer experimental results ${ }^{8}$ (blue inverted triangles) and recent theoretical values ( $\left(\operatorname{star}^{13}\right.$, pink crosses $^{15}$, and blue pluses ${ }^{14}$ for $\mathrm{H}$ and green pluses ${ }^{14}$ for $\mathrm{H}_{2} \mathrm{O}$; large and small symbols indicate maximum and minimum values, respectively) are also plotted. $\mathbf{b}$ Exchange coefficient $K_{\mathrm{D}}$ for Eq. 2. The numbers given to each datum point and regression line indicate pressure conditions.

estimates of the residual amount in the present-day mantle (291 $\mathrm{ppm})^{18}$, crust, oceans, and atmosphere $\left(1.6 \times 10^{24} \mathrm{~g}\right)^{19}$, altogether comprising the bulk silicate Earth (BSE) during accretion, gives a value of $687 \mathrm{ppm} \mathrm{H}_{2} \mathrm{O}$. If the Earth lost $0.1-1$ ocean mass of water $^{20,21}$ (OC) by escape of hydrogen to space, this estimate would be considered a lower bound for $\mathrm{H}_{2} \mathrm{O}$ concentrations prevailing in the MO. Acknowledging the many uncertainties in this estimate, we will use $687 \mathrm{ppm}_{2} \mathrm{O}$ in the proto-Earth BSE (Fig. 3) in order to examine how much hydrogen could plausibly have been incorporated into the Earth's core.

We calculated the amount of hydrogen that would be incorporated from silicates into metals based on three different core formation models. First we considered a conceptually simple, single-stage core formation model ${ }^{2-4}$ (see "Methods"), which reconciles the mantle abundances of moderately siderophile elements with entire core-mantle chemical equilibration taking place at a single $P, T$, and $\mathrm{fO}_{2}$ condition, around $50 \mathrm{GPa}$ and 3500 $\mathrm{K}$ (Supplementary Fig. 1 ) and $\Delta \mathrm{IW}=-2.3$. While such a model is physically unrealistic, it is nevertheless useful as a simple reference for comparison. With these assumptions, we estimate

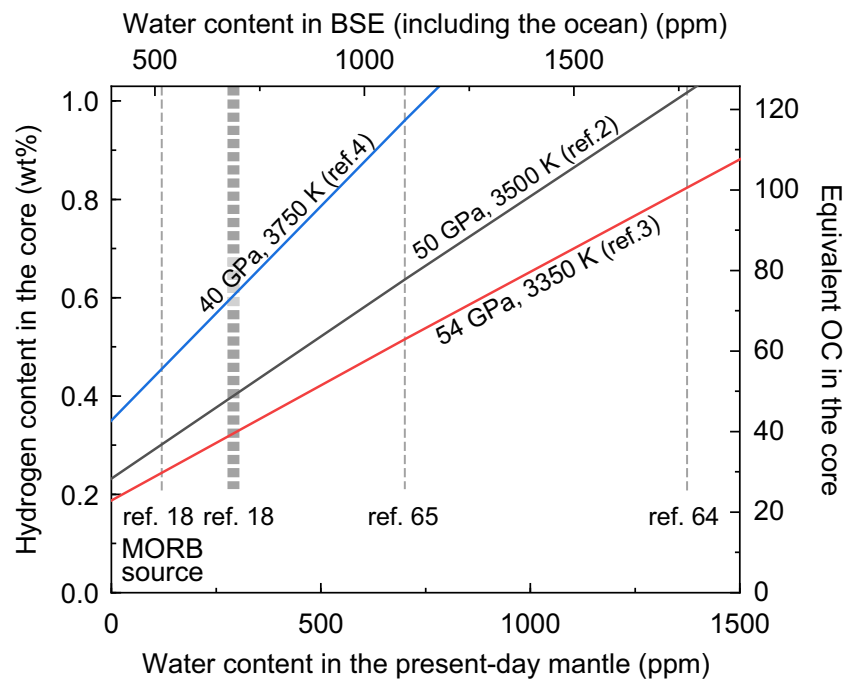

Fig. 3 Estimate of hydrogen concentration in the core based on singlestage core formation models. Three solid lines show our estimates of the hydrogen content in the core as a function of residual $\mathrm{H}_{2} \mathrm{O}$ abundance in silicates (= present-day BSE water content) at the labeled $P-T$ conditions $^{2-4}$. The BSE water content depends largely on the average mantle abundance (lower horizontal axis) ${ }^{18,64,65}$. Even a modest amount of

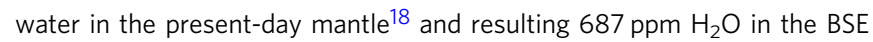
suggest $0.32-0.61 \mathrm{wt} \% \mathrm{H}$ in the core. The corresponding ocean mass of water $(\mathrm{OC})$ that includes an equivalent amount of hydrogen is also indicated (right vertical axis).

that a core forged under this scenario would contain $0.32-0.61 \mathrm{wt}$ $\% \mathrm{H}$ in equilibrium with molten silicate containing $687 \mathrm{ppm}_{2} \mathrm{O}$ (Fig. 3 and Supplementary Table 2).

Next we examined a continuous core formation model ${ }^{5}$ (Supplementary Fig. 4) in which core segregation occurred over 1000 accretion events and the impactor core equilibrated with the entire $\mathrm{MO}$ at $P-T$ conditions prevailing at its base (see "Methods"). We followed a specific model (path 6) given by Badro et al. ${ }^{5}$ for the evolution of $\mathrm{fO}_{2}$ in metal-silicate equilibration. Considering three different water delivery scenarios, we find that $0.3-0.6 \mathrm{wt} \% \mathrm{H}$ in the core is necessary to leave a residual budget of $\sim 690 \mathrm{ppm} \mathrm{H}_{2} \mathrm{O}$ in the BSE unless water was delivered only in the last stage of Earth accretion.

We also applied a multi-stage core formation model $^{6}$ (Fig. 4 and Supplementary Fig. 5), where metal-silicate partitioning took place by 1000 steps upon accretion of identical impactors having the same water abundance and the metal from each impactor equilibrated only with a limited fraction of silicate melt at the base of the existing MO (see "Methods"). In this model, $\mathrm{fO}_{2}$ is given as a consequence of the metal-silicate partitioning of $\mathrm{H}, \mathrm{Ni}, \mathrm{Co}, \mathrm{O}$, and $\mathrm{Si}$. We have explored reasonable sets of parametersimpactor size, final (maximum) $P$ at the bottom of the $\mathrm{MO}$, impactor's metal/oxide proportions of $\mathrm{Fe}$ and $\mathrm{Si}$, and $\mathrm{H}_{2} \mathrm{O}$ concentration (Supplementary Fig. 6 and Supplementary Table 3), which allow for a remaining $\sim 700 \mathrm{ppm} \mathrm{H}_{2} \mathrm{O}$ in the $\mathrm{BSE}$ and yielding the correct core mass and mantle $\mathrm{FeO}, \mathrm{Ni}$ and $\mathrm{Co}$ abundances. These accretion models imply that the core includes 0.27-0.56 wt\% H after accretion (Supplementary Table 4).

In summary, our new experimental determination of metal-silicate partitioning of hydrogen suggests $0.3-0.6 \mathrm{wt} \% \mathrm{H}$ was incorporated into the core, leaving $\sim 700 \mathrm{ppm} \mathrm{H}_{2} \mathrm{O}$ in a magma ocean, unless water was delivered only in the late stage of Earth accretion ${ }^{22}$. We would find more hydrogen in the core if magma oceans contained more water (Fig. 3). According to theoretical calculations ${ }^{23,24}$, a hydrogen-rich outer core is 

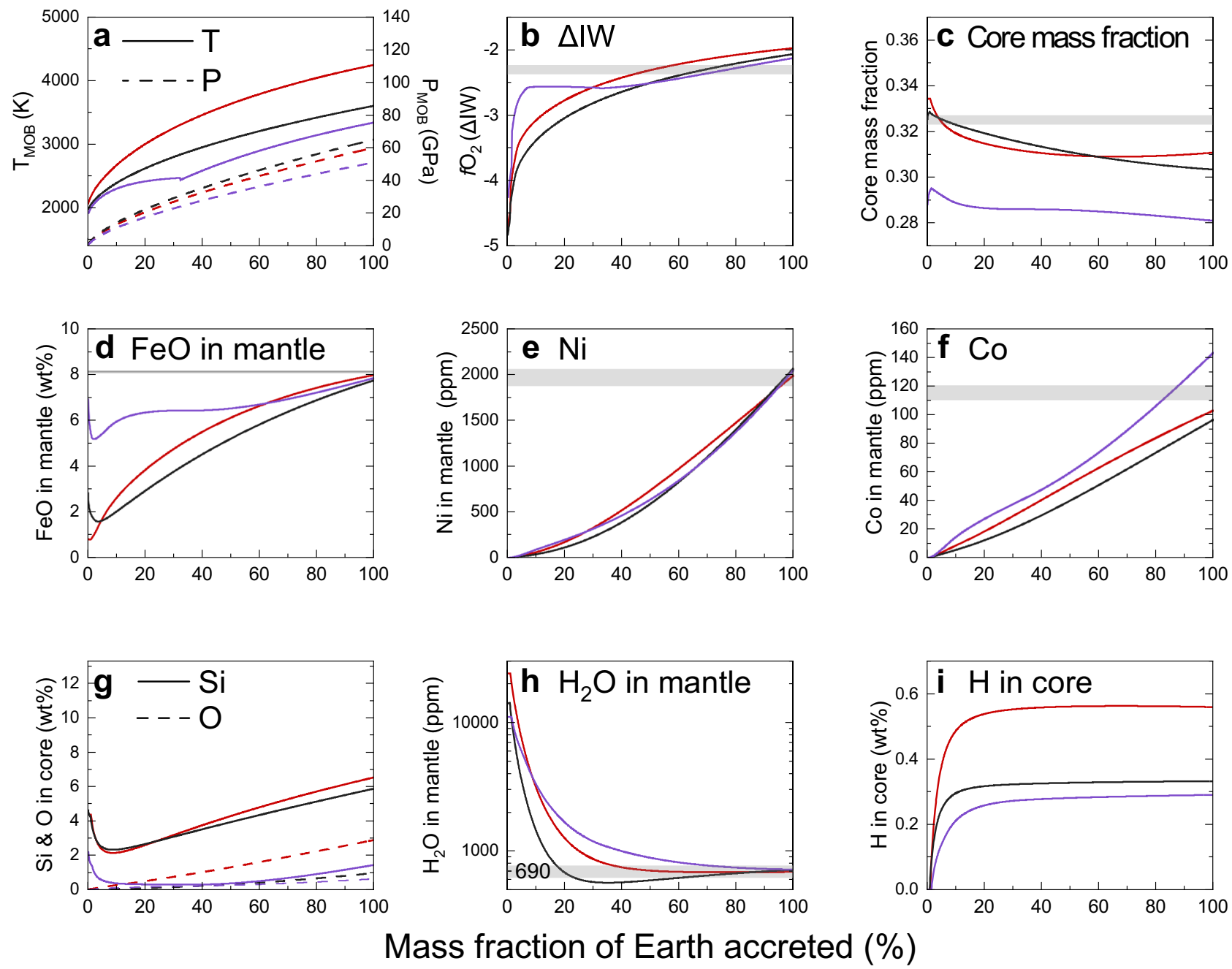

Fig. 4 Evolutions during multi-stage core formation. a $P$ and $T$ and $\mathbf{b} f \mathrm{O}_{2}$ conditions for metal-silicate equilibrium. c Core mass fraction. FeO (d), Ni (e), $\mathrm{Co}(\mathbf{f})$, and $\mathrm{H}_{2} \mathrm{O}(\mathbf{h})$ in the silicate; and $\mathrm{O}$ and $\mathrm{Si}(\mathbf{g})$ and $\mathrm{H}$ (i) in the core. Each model, S1 (red), F2 (black), and R3 (purple) in Supplementary Table 4 , employed a different combination of $P-T$ path (a) and partitioning data $2,3,6,57,63$ for elements other than hydrogen (see Supplementary Table 3 for each parameter set). The present Earth values are shown by gray bands.

compatible with seismological observations, with $0.3-0.6 \mathrm{wt} \% \mathrm{H}$ accounting for $30-60 \%$ of the density deficit and sound velocity excess of the outer core. A value of $0.3-0.6 \mathrm{wt} \% \mathrm{H}$ in the core is equivalent to the amount of hydrogen in $37-73$ OCs (Fig. 3), and an additional $\sim 2$ OCs are included in our assumed BSE (including the ocean itself). Such a large amount of water, corresponding to $0.9-1.7 \%$ Earth's mass, must have been delivered to our planet during accretion. The core is expected to have a lower $\mathrm{D} / \mathrm{H}$ than equilibrated silicates ${ }^{25}$, some of which may have leaked into the mantle ${ }^{26}$ along with other core-like isotopic signatures ${ }^{27}$. The delivery of a few tens to hundreds times OCs to the growing Earth is supported by some recent planet formation scenarios $28-30$. In addition, any terrestrial planets and moons greater than $\sim 10 \%$ of the Earth's mass may contain $>0.15 \mathrm{wt} \% \mathrm{H}$ in their metallic cores (Supplementary Fig. 5i) if they formed under conditions similar to that of Earth's formation and water was continuously supplied during accretion.

\section{Methods}

Starting materials. We used pure iron foil (5N, Mairon-UHP, Toho Zinc Co. Ltd.) and hydrous MORB glass as starting materials. MORB glasses containing about 0.2 and $1.0 \mathrm{wt} \% \mathrm{H}_{2} \mathrm{O}$ were synthesized using a piston-cylinder apparatus. The major element composition is similar to the one employed in previous experimental studies $^{31,32}$ (Supplementary Table 5). Water content in the glass was confirmed using SIMS analyses (see below).

High-pressure and -temperature experiments. Experiments were performed in a laser-heated DAC with flat $300 \mu \mathrm{m}$ culet diamond anvils. Iron foil (5-7 $\mu \mathrm{m}$ thick) was sandwiched between the hydrous MORB glass powder and loaded into a $\sim 140$ $\mu \mathrm{m}$ hole at the center of a pre-indented rhenium gasket. We used the MORB glass with $\sim 1.0 \mathrm{wt} \% \mathrm{H}_{2} \mathrm{O}$, except for run \#1 in which $\sim 0.6 \mathrm{wt} \% \mathrm{H}_{2} \mathrm{O}$ was added by mixing glass containing 0.2 and $1.0 \mathrm{wt} \% \mathrm{H}_{2} \mathrm{O}$. After loading the sample, the entire DAC was dried in a vacuum oven at $400 \mathrm{~K}$ for 3-8 h. As soon as the DAC was taken out of the oven, we immediately started compression.

The sample was heated at high pressure while collecting in situ XRD data at beamline BL10XU, SPring-8. Heating was applied from both sides using two $100 \mathrm{~W}$ single-mode $\mathrm{Yb}$ fiber lasers (SPI photonics). The laser beam was converted to a flattop distribution using beam shaping optics (New Focus). The laser spot size was around $40 \mu \mathrm{m}$. Heating duration was limited to $3 \mathrm{~s}$ to avoid temperature fluctuations that could give rise to complex melting textures. This is sufficient time for each element to diffuse in liquid metal ${ }^{33}$ and silicate ${ }^{34}$. Earlier time-series experiments $\mathrm{s}^{32}$ on element partitioning in a DAC also showed that partition coefficients did not change after heating for 1-2 s. Temperature was measured using a spectro-radiometric method, and a one-dimensional radial temperature profile was obtained across a laser-heated spot with $1 \mu \mathrm{m}$ spatial resolution. Experimental temperature was estimated by averaging over the $6 \mu \mathrm{m}$ span of the Xray beam. Temperature uncertainty ${ }^{35}$ may be $\pm 5 \%$. Sample pressure was determined from the Raman shift of the diamond anvil ${ }^{36}$ at ambient temperature after heating. We added an additional contribution of thermal pressure that has been estimated to be $+2.5 \mathrm{GPa}$ per $1000 \mathrm{~K}^{37}$. 
In situ XRD measurement and the hydrogen content in metal. XRD patterns were collected before/during/after heating in each run. A monochromatic X-ray beam with an energy of $\sim 30 \mathrm{keV}$ was focused to $6 \mu \mathrm{m}$ area (full-width at halfmaximum) on a sample position. The XRD data were collected every $0.22 \mathrm{~s}$ during heating on a flat panel detector (Perkin Elmer) (Fig. 1a).

Since hydrogen escapes from solid iron during decompression as it transforms into bcc $\mathrm{Fe}^{10,16}$ (Supplementary Fig. 2), hydrogen concentration must be measured at high pressure. The XRD patterns demonstrate that molten iron crystallized $\mathrm{FeH}_{X}$ and minor $\mathrm{FeOOH}$ upon quenching the temperature while maintaining compression (Fig. 1a). The disappearance of a diffuse signal suggests that quenched molten iron fully consisted of crystals even without thermal annealing. Therefore the $\mathrm{FeH}_{X}+$ minor $\mathrm{FeOOH}$ represents the bulk hydrogen concentration in metal. Hydrogen content in molten iron was therefore determined from (1) the proportions of solid $\mathrm{FeH}_{X}$ and $\mathrm{FeOOH}$ in quenched liquid iron and (2) the $X$ value in $\mathrm{FeH}_{X}$ that is calculated from its unit-cell volume at high pressure

(Supplementary Table 1). Earlier experiments have demonstrated that thermal annealing of such $\mathrm{FeH}_{X}$ quench crystals had a relatively small effect on their unitcell volume; hydrogen content $X$ derived from the lattice volume (see below) decreased from 1.21 to 1.14 upon heating to $\sim 1500 \mathrm{~K}$ at $65 \mathrm{GPa}^{17}$.

Here, hcp $\mathrm{FeH}_{X>1}$ and fcc $\mathrm{FeH}_{X<1}$ were formed in run \#4 and the other runs, respectively. Since hydrogen incorporation expands the volume of Fe, hydrogen concentration in $\mathrm{FeH}_{X}$ can be obtained ${ }^{38}$ as:

$$
X=\left(V_{\mathrm{FeH}_{X}}-V_{\mathrm{Fe}}\right) / \Delta V_{\mathrm{H}}
$$

where $V_{\mathrm{FeH}_{X}}$ is the volume of $\mathrm{FeH}_{X}$ per Fe atom and $\Delta V_{\mathrm{H}}$ is the volume increase per hydrogen atom ${ }^{39}$, consistent with recent neutron diffraction data ${ }^{40,41}$. The volume of pure $\mathrm{Fe}$ is from Dewaele et al. ${ }^{42}$ for hcp and from Tsujino et al. ${ }^{43}$ for fcc. The $X$ value was found to be homogeneous in the metal.

The unit-cell volume of $\varepsilon$-FeOOH was similar to that observed in recent highpressure studies at equivalent pressure ${ }^{44}$. Since $\mathrm{FeO}$ was not observed, the proportions of $\mathrm{FeH}_{X}$ and $\mathrm{FeOOH}$ are estimated from the $\mathrm{Fe}$ and $\mathrm{O}$ contents in quenched liquid iron that were obtained by electron probe micro-analyzer (EPMA) analyses (see below).

SIMS analysis and the hydrogen content in silicate melt. After recovering the DAC sample at ambient conditions, a cross-section at the center of the laser-heated portion was prepared parallel to the compression/laser-heating axis by using a dual-beam focused ion beam (FIB, Versa 3D ${ }^{\mathrm{TM}}$, FEI). Textural observation and preliminary compositional characterization were made with a field-emission-type scanning electron microscope (FE-SEM) and an energy-dispersive X-ray spectrometer (EDS) with a silicon drift detector (Bruker) in the dual-beam FIB system (Supplementary Fig. 3).

Subsequently the hydrogen content in a quenched silicate melt was determined with an isotope microscope system installed at the Hokkaido University, which is composed of CAMECA IMS-1270 SIMS and a two-dimensional ion detector, SCAPS (stacked CMOS-type active pixel sensor) ${ }^{45}$. This system provides quantitative maps of secondary ions emitted from sample surface ${ }^{46,47}$ (Fig. 1b), because the CMOS sensor exhibits a good linear relationship between an output voltage and the number of secondary ions ${ }^{48}$ ). Therefore, we can quantify the abundance of each element from the intensity map.

Two-dimensional images of ${ }^{1} \mathrm{H}^{+},{ }^{28} \mathrm{Si}^{+}$, and ${ }^{40} \mathrm{Ca}^{+}$with $0.5-1.2 \mu \mathrm{m}$ spatial resolution for ${ }^{1} \mathrm{H}^{+}$were collected using the ${ }^{16} \mathrm{O}^{-}$primary beam $(13 \mathrm{keV}, 37 \mathrm{nA})$ that was focused to $20-30 \mu \mathrm{m}$ in diameter and rastered across a $100 \mu \mathrm{m} \times 100 \mu \mathrm{m}$ region on the sample surface. We set the contrast aperture to be $100 \mu \mathrm{m}$ in diameter with the exit slit fully opened. In order to minimize the effect of adsorbed water on the sample surface, we employed the energy slit to be $\pm 20 \mathrm{eV}$ to select kinetic energy ranges of secondary ions from 80 to $120 \mathrm{eV}$ by loading a sample offset voltage of $-100 \mathrm{~V}$. The pressure during measurements was $6.5-8.0 \times 10^{-8}$ $\mathrm{Pa}$. Secondary ion images of ${ }^{1} \mathrm{H}^{+},{ }^{28} \mathrm{Si}^{+}$, and ${ }^{40} \mathrm{Ca}$ were obtained sequentially in the following order; ${ }^{28} \mathrm{Si}^{+},{ }^{1} \mathrm{H}^{+},{ }^{28} \mathrm{Si}^{+},{ }^{1} \mathrm{H}^{+},{ }^{28} \mathrm{Si}^{+}$, and ${ }^{40} \mathrm{Ca}^{+}$. Accumulation time was 500 and $100 \mathrm{~s}$ in each image, and two and three images were combined to calculate concentration maps for ${ }^{1} \mathrm{H}^{+}$and ${ }^{28} \mathrm{Si}^{+}$, respectively.

Hydrogen concentration in the quenched silicate melt was quantified from the ${ }^{1} \mathrm{H} /{ }^{28} \mathrm{Si}$ intensity ratio using a calibration curve established by three silicate glasses with known $\mathrm{H}_{2} \mathrm{O}$ concentrations $(0.00-4.5 \mathrm{wt} \%)^{49}$ (Supplementary Fig. 7). The analyses of these standards provide a linear relation between the count and known ${ }^{1} \mathrm{H} /{ }^{28} \mathrm{Si}$ ratios; a correlation coefficient $R^{2}=0.996$. The detection limit of $\mathrm{H}_{2} \mathrm{O}$ is 15 ppm from its $y$-intercept. These standards were measured before, during, and after the analysis of each DAC sample. In order to reduce statistical errors for each DAC sample, regions of interest (ROIs) were selected on the quenched silicate melt. Combining the ${ }^{1} \mathrm{H} /{ }^{28} \mathrm{Si}$ intensity ratio with the $\mathrm{Si}$ content obtained by a fieldemission-type electron probe micro-analyzer (FE-EPMA, see below), hydrogen (water) concentration in silicate melt was determined with $\pm 2 \%$ to $\pm 7 \%$ uncertainty, depending on its abundance (Supplementary Table 1).

Chemical analysis with FE-EPMA. The major element compositions, except hydrogen, of both quenched liquid metal and silicate melt were determined using an FE-EPMA (JXA-8530F, JEOL) (Supplementary Tables 5 and 6). Analyses were performed with an acceleration voltage of $12 \mathrm{keV}$ and a beam current of $15 \mathrm{nA}$. For metal, we used an electron beam diameter of $3 \mu \mathrm{m}, \mathrm{Fe}, \mathrm{Al}_{2} \mathrm{O}_{3}, \mathrm{Ni}_{2} \mathrm{Si}$, and $\mathrm{Mg}$ as standards, and LIFH $(\mathrm{Fe}), \operatorname{LDE} 1 \mathrm{H}(\mathrm{O})$, PETJ $(\mathrm{Si})$, and TAP $(\mathrm{Al}, \mathrm{Mg})$ as analyzing crystals. For silicate, the standards were $\mathrm{SiO}_{2}, \mathrm{TiO}_{2}, \mathrm{Al}_{2} \mathrm{O}_{3}, \mathrm{Fe}_{2} \mathrm{O}_{3}, \mathrm{MgO}, \mathrm{CaSiO}_{3}$, $\mathrm{NaAlSi}_{3} \mathrm{O}_{8}$, and $\mathrm{KAISi}_{3} \mathrm{O}_{8}$, and the analyzing crystals were TAP ( $\mathrm{Si}, \mathrm{Mg}, \mathrm{Na}$ ), PETJ (Ti, K), TAPH (Al), LIFH ( $\mathrm{Fe}$ ), and PETH (Ca). We employed the EDS analyses of oxygen and silicon only for run \#2, because the metal part was sputtered out during SIMS analyses. In addition, the carbon contents in metal were determined separately without carbon-coating using the LDE2 analyzing crystal and $\mathrm{Fe}_{3} \mathrm{C}$ as a standard ${ }^{17}$.

\section{Activities of elements in hydrogen-rich metal and oxygen fugacity. The} hydrogen content $X$ in $\mathrm{FeH}_{X}$ ranged from 0.23 to 1.78 in the present study (Supplementary Table 1). Large $X$ significantly decreases the molar fractions of $\mathrm{Fe}$ and $\mathrm{O}$ in metal. And, it apparently increases the oxygen fugacity $\Delta \mathrm{IW} \approx$

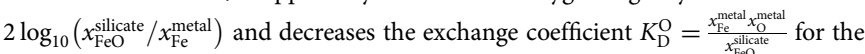
reaction $\mathrm{FeO}^{\text {silicate }}=\mathrm{Fe}^{\text {metal }}+\mathrm{O}^{\text {metal }}$

We obtain the $K_{\mathrm{D}}^{\mathrm{O}}$ values from this study using molar fractions of iron and oxygen in metal, with and without considering the presence of hydrogen and carbon. They are compared with the results of Fischer et al. ${ }^{3}$ that were obtained in the absence of hydrogen and carbon (Supplementary Fig. 8). The present $K_{\mathrm{D}}^{\mathrm{O}}$ values that do not take hydrogen and carbon into account are closer to their data, suggesting that hydrogen and carbon do not have colligative properties in iron solvent. It is likely because the incorporation of small $\mathrm{H}$ and $\mathrm{C}$ atoms in liquid $\mathrm{Fe}$ is interstitial rather than substitutional unlike other larger atoms ${ }^{23}$. Therefore, in this study, we approximate the activity of element $i$ in metal as:

$$
x_{i}^{\prime}=\frac{N_{i}}{\sum_{k \neq \mathrm{H}, \mathrm{C}} N_{k}}
$$

Note that this formulation has been conventionally used in solid metalhydrogen systems $\mathrm{s}^{50}$. The slope on a plot $\log _{10} D$ vs. $\Delta \mathrm{IW}$ obtained with this formulation indicates a valence state of 0.999 for hydrogen in the silicate melt (Supplementary Fig. 9), which supports the validity of the present estimate of the activities of elements in metal and silicate. Our experiments give $\log _{10} K_{\mathrm{D}}^{\mathrm{O}}=a+$ $b / T$, where $a=0.37$ (18) and $b=-1535$ (687).

Single-stage core formation model. Single-stage core formation models $\mathrm{s}^{2-4}$ assume the entire core and mantle equilibrate at a single $P, T$, and $f \mathrm{O}_{2}$ condition. We employed three different $P-T$ conditions at fixed $f \mathrm{O}_{2}(\Delta \mathrm{IW}=-2.3)$ that is compatible with the $\mathrm{FeO}$ content of the mantle (Supplementary Table 2), which have been proposed on the basis of different sets of partitioning data for siderophile elements ${ }^{2-4}$. The present experiments demonstrate that hydrogen is strongly siderophile under these conditions; the metal/silicate partition coefficient $D_{\mathrm{H}}^{*}$ ranges from 38 to 70 (Supplementary Fig. 1) (see its caption for $D_{\mathrm{H}}^{*}$ that is defined for simplicity). Previous studies ${ }^{2-4}$ have already calculated the partitioning of $\mathrm{O}$ and $\mathrm{Si}$. We assume that the presence of $\mathrm{H}$ and $\mathrm{H}_{2} \mathrm{O}$ does not change the partitioning of siderophile elements ${ }^{51,52}, \mathrm{O}$ (Supplementary Fig. 8) and Si.

Our calculations give $0.32-0.61 \mathrm{wt} \% \mathrm{H}$ in the core when equilibrated with a KLB-1 pyrolitic melt ${ }^{33}$ containing $687 \mathrm{ppm} \mathrm{H}_{2} \mathrm{O}$ (Fig. 3). The resulting core also includes 0 (assumed) $-2.5 \mathrm{wt} \% \mathrm{O}$ and $4.5-13.3 \mathrm{wt} \% \mathrm{Si}$, in addition to $0.32-0.61 \mathrm{wt} \% \mathrm{H}$ and likely $2.0 \mathrm{wt} \% \mathrm{~S}$ that is inferred from cosmo-/geochemical argument ${ }^{54}$ (Supplementary Table 2). This liquid is less dense than the present outer core ${ }^{24,55}$, possibly suggesting that it later become depleted in $\mathrm{Si}+\mathrm{O}$ following $\mathrm{SiO}_{2}$ crystallization ${ }^{56}$.

Continuous core formation model. The continuous core formation model considers that the Earth accreted incrementally and the metal in each impactor chemically equilibrated with the entire magma ocean (MO). The $P-T$ conditions are assumed to correspond to the base of the $\mathrm{MO}^{4,5}$. While Wade and Wood ${ }^{4}$ argued that the oxidation state for core segregation was initially reductive and became progressively more oxidative to the current state $(\Delta \mathrm{IW}=-2.3)$, Badro et al. ${ }^{5}$ demonstrated that starting with oxidative conditions can better explain the mantle abundances of moderately siderophile elements on the basis of metal-silicate partitioning experiments at higher pressures ${ }^{57}$.

We performed 1000-step calculations of metal-silicate partitioning of hydrogen at evolving $P, T$, and $f_{2}$ conditions following path 6 in Badro et al. ${ }^{5}$; for $i^{\text {th }}$ step, $P_{\mathrm{MOB}, i}=P_{\text {final }} \times(i / 1000)^{2 / 3}\left(P_{\text {final }}=62 \mathrm{GPa}\right)$ and $T_{\mathrm{MOB} 1, i}=2022+54.21 P_{\mathrm{MOB}, i}-$ $0.34 P_{\mathrm{MOB}, i}^{2}+9.0747 \times 10^{-4} P_{\mathrm{MOB}, i}^{3}(\mathrm{~K})$ (Supplementary Fig. 1), which explains the mantle abundances of $\mathrm{Ni}, \mathrm{Co}, \mathrm{V}$, and $\mathrm{Cr}$ as well as $\mathrm{FeO}$. Details are found in Dauphas ${ }^{58}$. Each impactor possesses $32.5 \mathrm{wt} \%$ metal (same as the present-day Earth). Silicate composition is pyrolitic ${ }^{59}$ except for $\mathrm{FeO}$ that is controlled by $\mathrm{fO}_{2}$ in the model. Evolution of the Si and $\mathrm{O}$ abundances in the core are shown in Fig. S2 in Badro et al. ${ }^{5}$. The effects of $\mathrm{H}_{2} \mathrm{O}$ and $\mathrm{H}$ on metal/silicate partitioning of the other elements are not considered (see $e^{51,52}$ and Supplementary Fig. 8). According to Iizuka-Oku et al..$^{10}$ and Fukai and Suzuki ${ }^{16}$, no hydrogen is partitioned into metal when $P_{\mathrm{MOB}, i}<3 \mathrm{GPa}$.

Three different scenarios were considered for the delivery of water: (1) constant, (2) linearly increases, and (3) none but the last seven impactors (Supplementary Fig. 4a). For each scenario, we have examined hydrogen concentrations in the core when $\sim 690 \mathrm{ppm} \mathrm{H}_{2} \mathrm{O}$ remains in the silicate after accretion (Supplementary Fig. 4b). For scenario 1, hydrogen concentration in the core is almost constant at $0.60 \mathrm{wt} \%$ during accretion (Supplementary Fig. 4c). While $0.30 \mathrm{wt} \% \mathrm{H}$ is found in 
the core with scenario 2 , only $25 \mathrm{ppm}$ is present in scenario 3 . It is possible that water derives predominantly from a late veneer after core formation ${ }^{22}$, leading to the minimal incorporation of hydrogen into the core.

Multi-stage core formation model. We also examined the multi-stage core formation model, in which core segregation occurred by multiple steps upon accretional impacts and each time impactor core metal equilibrated with a limited portion of silicate in the existing MO at the $P-T$ condition of its base $e^{6,60}$. While Rubie et al. ${ }^{6}$ assumed that hydrogen is not siderophile and employed $D_{\mathrm{H}}=$ $0.05-0.5$, we apply $D_{\mathrm{H}}>34$ above $3 \mathrm{GPa}$ when following the same $P-T$ evolution for metal-silicate equilibration in this study.

Our calculations followed the concepts of Rubie et al. ${ }^{60}$ except that impactor size and composition does not change during accretion. Upon each impact on the protoEarth, an impactor core sinks in a descending plume, which expands with increasing depth as more silicate melt is turbulently entrained (see Fig. 2 in Deguen et al. ${ }^{61}$ ). The equilibrium efficiency between impactor metal and the proto-Earth's silicate is controlled by $\Gamma$ at each step, which is the ratio of the mass of equilibrated silicate over the mass of each impactor core. We performed 1000-step calculations of metal-silicate partitioning, with $N(1-10)$ impactors for each step.

At $i^{\text {th }}$ step, $\Gamma_{i}$ is obtained as follows. The volume fraction of metal $\left(\varphi_{\text {metal }, i}\right)$ in such metal + silicate composite plume when it reaches the bottom of the MO is given by Deguen et al. ${ }^{61}$,

$$
\varphi_{\text {metal }, i}=\left(\frac{r_{\text {imp core }}}{r_{\text {plume }}}\right)^{3}=\left(1+\frac{\alpha Z_{i}}{r_{\text {imp core }}}\right)^{-3}
$$

in which $\alpha=0.25, Z_{i}$ is depth of the MO, and $r_{\text {imp core }}$ is the radius of impactor's core. $r_{\text {imp core }}$ is formulated as:

$$
r_{\text {imp core }}=\left[\frac{m_{\text {imp }}-\frac{4}{3} \pi \times r_{\text {imp }}^{3} \times \rho_{\text {imp silicate }}}{\frac{4}{3} \pi \times\left(\rho_{\text {imp core }}-\rho_{\text {imp silicate }}\right)}\right]^{1 / 3}
$$

with impactor's entire mass $m_{\mathrm{imp}}(=1 / 1000 / N \times$ Earth's mass $)$, silicate and core densities $\rho_{\text {imp silicate }}=(1.446 / 1000 / \mathrm{N}+3) \times 10^{3}\left(\mathrm{~kg} \mathrm{~m}^{-3}\right)$ and $\rho_{\text {imp core }}=2.5 \times$ $\rho_{\text {imp silicate }}{ }^{6}$ and entire radius $r_{\text {imp }}$ of the impactor,

$$
r_{\text {imp }}=\left[\frac{m_{\text {imp silicate }}+0.4 m_{\text {imp core }}}{\frac{4}{3} \pi \times \rho_{\text {imp silicate }}}\right]^{1 / 3}
$$

Both the mass of impactor silicate and core, $m_{\text {imp silicate }}$ and $m_{\text {imp core }}$ are obtained when $\Phi_{\mathrm{Fe}}, \Phi_{\mathrm{Si}}$ (the proportions of metallic Fe and Si with respect to all $\mathrm{Fe}$ and $\mathrm{Si}$ ) and $\mathrm{H}_{2} \mathrm{O}$ concentration of the impactor are given. $r_{\text {imp }}$ is found, for example, to be $408 \mathrm{~km}$ when $\Phi_{\mathrm{Fe}}=0.99, \Phi_{\mathrm{Si}}=0.17, \mathrm{H}_{2} \mathrm{O}=1.1 \mathrm{wt} \%$ and $N=1$ (Supplementary Table 3). It could be argued that the average impactor size during Earth accretion was smaller $(N>1)$ considering the biggest asteroid Ceres is 473 $\mathrm{km}$ in radius.

$Z_{i}$, the depth of the MO at step $i$, is given as $r_{\mathrm{pEarth}, i}-r_{\mathrm{MOB}, i} \cdot r_{\mathrm{pEarth}, i}$ is the radius of the entire embryo (proto-Earth), which is calculated using Eq. 7 with its silicate density $\rho_{\text {pEarth silicate }, i}=(1.446 \times i / 1000+3) \times 10^{3}\left(\mathrm{~kg} \mathrm{~m}^{-3}\right)$ and the mass of its silicate and core, $m_{\mathrm{pEarth}}$ silicate, $i$ and $m_{\mathrm{pEarth}}$ core, $i$, that are calculated at each step. $r_{\mathrm{MOB},}$, the radius of the bottom of the MO, was obtained from the following equations with corresponding pressure $P_{\mathrm{MOB}, i}=P_{i}(\mathrm{GPa})$ for metal-silicate equilibrium ${ }^{5,62}$,

$$
\begin{aligned}
P_{\mathrm{MOB}, i} \times 10^{9}= & P_{\text {final }} \times\left(\frac{i}{1000}\right)^{2 / 3} \times 10^{9} \\
= & \frac{4}{3} \pi G \rho_{\mathrm{pEarth} \mathrm{silicate}, i} r_{\mathrm{MOB}, i}^{3}\left(\rho_{\mathrm{pEarth} \mathrm{core}, i}-\rho_{\mathrm{pEarth} \mathrm{silicate}, i}\right)\left(\frac{1}{r_{\mathrm{MOB}, i}}-\frac{1}{r_{\mathrm{pEEarth}, i}}\right) \\
& +\frac{2}{3} \pi G \rho_{\mathrm{pEarth} \mathrm{silicate}, i}^{2}\left(r_{\mathrm{pEarth}, i}^{2}-r_{\mathrm{MOB}, i}^{2}\right)
\end{aligned}
$$

with gravitational constant $G$. For example, in an embryo with 1/10 Earth's mass and a radius of $\sim 3200 \mathrm{~km}$, the depths of the core-mantle boundary and the bottom of the $\mathrm{MO}\left(Z_{100}\right)$ are $\sim 1500$ and $\sim 900 \mathrm{~km}$, respectively, depending on $\Phi_{\mathrm{Fe}}$ and $\Phi_{\mathrm{Si}}$.

Finally $\Gamma_{i}$ is obtained as:

$$
\Gamma_{i}=\frac{m_{\text {equilibrated silicate }}^{\prime}}{m_{\text {imp core }}^{\prime}}=\frac{\frac{4}{3} \pi r_{\text {imp core }}^{\prime 3} \times\left(\frac{1}{\varphi_{\text {metal }, i}}-1\right) \times \rho_{\text {pEarth silicate }, i}}{m_{\text {imp core }}^{\prime}}
$$

with $\varphi_{\text {metal }, i}$ (Eq. 5) and the radius $r_{\text {imp core }}^{\prime}$ and mass $m_{\text {imp core of combined } N}^{\prime}$ impactors accreting in each 1/1000 step of metal-silicate partitioning. Eq. 9 indicates that $\Gamma_{i}$ is larger (impactor core reacts with more silicate) when $\varphi_{\text {metal, } i}$ (namely, impactor size) is smaller. In addition, we considered that the impactor's silicate was preferentially involved in the chemical reaction with the impactor metal in the MO (Supplementary Fig. 10).

We have calculated the partitioning of $\mathrm{H}, \mathrm{Ni}, \mathrm{Co}, \mathrm{O}$, and $\mathrm{Si}$ between the impactor metal and equilibrated silicate (whose mass is obtained by $\Gamma_{i}$ ) under $P_{\mathrm{MOB}, i}=$ $P_{\text {final }} \times(i / 1000)^{2 / 3}$ and three different $T$ at each step (Supplementary Fig. 1$)$ :
(1) $T_{\mathrm{MOB} 1, i}=$ (same as that for the continuous core formation model above).

(2) $T_{\mathrm{MOB} 2, i}=1940 \times\left(P_{\mathrm{MOB}, i} / 29+1\right)^{1 / 1.9}$.

(3) $\quad T_{\mathrm{MOB} 3, i}=\left\{\begin{array}{c}1874+55.43 P_{\mathrm{MOB}, i}-1.74 P_{\mathrm{MOB}, i}^{2}+0.0193 P_{\mathrm{MOB}, i}^{3}(<24 \mathrm{GPa}) \\ 1249+58.28 P_{\mathrm{MOB}, i}-0.395 P_{\mathrm{MOB}, i}^{2}+0.0011 P_{\mathrm{MOB}, i}^{3}(\geq 24 \mathrm{GPa})\end{array}\right.$

For each of the three $T_{\text {МОв }}$ profiles, three different sets of metal-silicate partitioning data for $\mathrm{Ni}, \mathrm{Co}, \mathrm{O}$, and $\mathrm{Si}^{2}, 3,6,57,63$ were applied. Each impactor had a $\mathrm{Cl}$ chondritic-like composition for refractory elements (see Table S1 in Rubie et al. ${ }^{6}$ ).

The evolution of $f \mathrm{O}_{2}$ was calculated as $\Delta \mathrm{IW} \approx-2 \log _{10} \frac{x_{\mathrm{Fi}}^{\prime \text { metal }}}{x_{\text {ficate }}^{\text {sice }}}\left(\right.$ molar fraction $x^{\prime}$ does not consider $\mathrm{H}$ in metal, see above) at each step, which is the consequences of the incorporation of $\mathrm{H}, \mathrm{Si}$, and $\mathrm{O}$ into core-forming metal and of $\mathrm{Ni}, \mathrm{Co}$ and $\mathrm{Fe}$ into silicate. We did not consider the partitioning of $\mathrm{S}$ into silicate nor that of $\mathrm{Al}, \mathrm{Mg}$, and $\mathrm{Ca}$ into metal. We assumed that metal-silicate partitioning was not affected by the presence of $\mathrm{H}$ and $\mathrm{H}_{2} \mathrm{O}$ (see $\mathrm{e}^{51,52}$ and Supplementary Fig. 8).

We have explored parameter sets of $N, P_{\text {final }}$, and impactor's $\Phi_{\mathrm{Fe}}, \Phi_{\mathrm{Si}}$, and $\mathrm{H}_{2} \mathrm{O}$ concentration, which explain the residual silicate abundances of $\sim 700 \mathrm{ppm} \mathrm{H}_{2} \mathrm{O}$, $\sim 8.1 \mathrm{wt} \% \mathrm{FeO}, \sim 2000 \mathrm{ppm} \mathrm{Ni}$, and $\sim 100 \mathrm{ppm} \mathrm{Co}{ }^{59}$ (Fig. 4 and Supplementary Fig. 5). The mass fraction of the core, containing $\sim 2 \mathrm{wt} \% \mathrm{~S}^{54}$ in addition to $\mathrm{H}, \mathrm{Ni}$, $\mathrm{Co}, \mathrm{O}$, and $\mathrm{Si}$, was targeted to be 0.325 . Supplementary Fig. 6 shows parameters search maps for reductive, moderate and oxidative impactor cases. With $N=3$, $T_{\mathrm{MOB} 1}$ and metal-silicate partitioning data reported by Siebert et al. ${ }^{2,57}$, homogeneous accretions of reductive but water-bearing impactors best explain the Earth's composition (the evolution during accretion is given in Supplementary Data 1). We found a reasonable parameter set for each combination of three different $P-T$ paths and three different sets of partitioning data ${ }^{2,3,6,57,63}$ as listed in Supplementary Table 3. These calculations show that hydrogen concentration ranges from 0.27 to $0.56 \mathrm{wt} \%$ in the Earth's core (Supplementary Table 4). The evolutions of $P, T$, and $f \mathrm{O}_{2}$ conditions for metal-silicate equilibrium, core mass fraction, the $\mathrm{FeO}, \mathrm{Ni}, \mathrm{Co}$, and $\mathrm{H}_{2} \mathrm{O}$ contents in the magma ocean, and the $\mathrm{O}, \mathrm{Si}$, and $\mathrm{H}$ abundances in the core are illustrated in Fig. 4 and Supplementary Fig. 5.

Pressure and temperature effects on hydrogen partitioning using previous low-pressure data along with the present results. We also estimated the effects of $P$ and $T$ on metal-silicate partitioning of hydrogen using earlier low-pressure multi-anvil experimental data ${ }^{12}$ along with the present results. The exchange coefficient $K_{\mathrm{D}}$ is written as

$$
\log _{10} K_{\mathrm{D}}=0.692(986)-4590(1690) / T(\mathrm{~K})+141(43) \times P(\mathrm{GPa}) / T(\mathrm{~K})
$$

They are compared with those obtained only from our data in Supplementary Fig. 11

With such parameters, we have additionally calculated the amount of hydrogen incorporated into the core on the basis of a multi-stage core formation model that is similar to model \#S1 except for the $K_{\mathrm{D}}$ value (Supplementary Fig. 12, and Supplementary Tables 3 and 4 ). The results show $0.34 \mathrm{wt} \% \mathrm{H}$ in the core, consistent with those obtained by other simulations.

\section{Data availability}

The data supporting the main findings of this study are available in the paper and it's Supplementary Information. Any additional data can be available from the corresponding authors upon reasonable request.

Received: 30 July 2020; Accepted: 19 February 2021; Published online: 11 May 2021

\section{References}

1. Bouhifd, M. A. \& Jephcoat, A. P. Convergence of Ni and Co metal-silicate partition coefficients in the deep magma-ocean and coupled silicon-oxygen solubility in iron melts at high pressures. Earth Planet. Sci. Lett. 307, 341-348 (2011).

2. Siebert, J., Badro, J., Antonangeli, D. \& Ryerson, F. J. Metal-silicate partitioning of $\mathrm{Ni}$ and $\mathrm{Co}$ in a deep magma ocean. Earth Planet. Sci. Lett. 321-322, 189-197 (2012).

3. Fischer, R. A. et al. High pressure metal-silicate partitioning of $\mathrm{Ni}, \mathrm{Co}, \mathrm{V}, \mathrm{Cr}$, Si, and O. Geochim. Cosmochim. Acta 167, 177-194 (2015).

4. Wade, J. \& Wood, B. J. Core formation and the oxidation state of the Earth. Earth Planet. Sci. Lett. 236, 78-95 (2005).

5. Badro, J., Brodholt, J. P., Piet, H., Siebert, J. \& Ryerson, F. J. Core formation and core composition from coupled geochemical and geophysical constraints. Proc. Natl Acad. Sci. USA 112, 12310-12314 (2015).

6. Rubie, D. C. et al. Accretion and differentiation of the terrestrial planets with implications for the compositions of early-formed Solar System bodies and accretion of water. Icarus 248, 89-108 (2015).

7. Li, J. \& Fei, Y. Experimental constraints on core composition. In Treatise on Geochemistry 2nd edn, Vol. 3 (eds. Holland, H. D. \& Turekian, K. K.) 527-557 (Elsevier, 2014)

8. Okuchi, T. Hydrogen partitioning into molten iron at high pressure: implications for Earth's core. Science 278, 1781-1784 (1997). 
9. Shibazaki, Y., Ohtani, E., Terasaki, H., Suzuki, A. \& Funakoshi, K. Hydrogen partitioning between iron and ringwoodite: implications for water transport into the Martian core. Earth Planet. Sci. Lett. 287, 463-470 (2009).

10. Iizuka-Oku, R. et al. Hydrogenation of iron in the early stage of Earth's evolution. Nat. Commun. 8, 14096 (2017).

11. Clesi, V. et al. Low hydrogen contents in the cores of terrestrial planets. Sci. Adv. 4, e1701876 (2018)

12. Malavergne, V. et al. Experimental constraints on the fate of $\mathrm{H}$ and $\mathrm{C}$ during planetary core-mantle differentiation. Implications for the Earth. Icarus 321, 473-485 (2019).

13. Zhang, Y. \& Yin, Q.-Z. Carbon and other light element contents in the Earth's core based on first-principles molecular dynamics. Proc. Natl Acad. Sci. USA 109, 19579-19583 (2012).

14. Li, Y., Vočadlo, L., Sun, T. \& Brodholt, J. P. The Earth's core as a reservoir of water. Nat. Geosci. 13, 453-458 (2020).

15. Yuan, L. \& Steinle-Neumann, G. Strong sequestration of hydrogen into the Earth's core during planetary differentiation. Geophys. Res. Lett. 47, e2020GL088303 (2020).

16. Fukai, Y. \& Suzuki, T. Iron-water reaction under high pressure and its implication in the evolution of the Earth. J. Geophys. Res. 91, 9222 (1986).

17. Hirose, K. et al. Hydrogen limits carbon in liquid iron. Geophys. Res. Lett. 46, 5190-5197 (2019).

18. Hirschmann, M. M. Constraints on the early delivery and fractionation of Earth's major volatiles from $\mathrm{C} / \mathrm{H}, \mathrm{C} / \mathrm{N}$, and $\mathrm{C} / \mathrm{S}$ ratios. Am. Mineral. 101 , 540-553 (2016).

19. Lécuyer, C., Gillet, P. \& Robert, F. The hydrogen isotope composition of seawater and the global water cycle. Chem. Geol. 145, 249-261 (1998).

20. Pope, E. C., Bird, D. K. \& Rosing, M. T. Isotope composition and volume of Earth's early oceans. Proc. Natl Acad. Sci. USA 109, 4371-4376 (2012).

21. Zahnle, K. J., Gacesa, M. \& Catling, D. C. Strange messenger: a new history of hydrogen on Earth, as told by xenon. Geochim. Cosmochim. Acta 244, 56-85 (2019).

22. Wang, Z. \& Becker, H. Ratios of S, Se and Te in the silicate Earth require a volatile-rich late veneer. Nature 499, 328-331 (2013)

23. Umemoto, K. \& Hirose, K. Liquid iron-hydrogen alloys at outer core conditions by first-principles calculations. Geophys. Res. Lett. 42, 7513-7520 (2015).

24. Umemoto, K. \& Hirose, K. Chemical compositions of the outer core examined by first principles calculations. Earth Planet. Sci. Lett. 531, 116009 (2020)

25. Wu, J. et al. Origin of Earth's water: chondritic inheritance plus nebular ingassing and storage of hydrogen in the core. J. Geophys. Res. Planets 123 2691-2712 (2018).

26. Hallis, L. J. et al. Evidence for primordial water in Earth's deep mantle. Science 350, 336-339 (2015).

27. Mundl-Petermeier, A. et al. Anomalous ${ }^{182} \mathrm{~W}$ in high ${ }^{3} \mathrm{He} /{ }^{4} \mathrm{He}$ ocean island basalts: fingerprints of Earth's core? Geochim. Cosmochim. Acta 271, 194-211 (2020).

28. Walsh, K. J., Morbidelli, A., Raymond, S. N., O’Brien, D. P. \& Mandell, A. M. A low mass for Mars from Jupiter's early gas-driven migration. Nature 475, 206-209 (2011).

29. Sato, T., Okuzumi, S. \& Ida, S. On the water delivery to terrestrial embryos by ice pebble accretion. Astron. Astrophys. 589, A15 (2016).

30. Raymond, S. N., Quinn, T. \& Lunine, J. I. High-resolution simulations of the final assembly of Earth-like planets. 2. Water delivery and planetary habitability. Astrobiology 7, 66-84 (2007)

31. Hirose, K., Fei, Y., Ma, Y. \& Mao, H. The fate of subducted basaltic crust in the Earth's lower mantle. Nature 397, 53-56 (1999).

32. Tateno, S. et al. Melting phase relations and element partitioning in MORB to lowermost mantle conditions. J. Geophys. Res. Solid Earth 123, 5515-5531 (2018).

33. Helffrich, G. Outer core compositional layering and constraints on core liquid transport properties. Earth Planet. Sci. Lett. 391, 256-262 (2014)

34. de Koker, N. P., Stixrude, L. \& Karki, B. B. Thermodynamics, structure, dynamics, and freezing of $\mathrm{Mg}_{2} \mathrm{SiO}_{4}$ liquid at high pressure. Geochim. Cosmochim. Acta 72, 1427-1441 (2008).

35. Mori, Y. et al. Melting experiments on $\mathrm{Fe}-\mathrm{Fe}_{3} \mathrm{~S}$ system to $254 \mathrm{GPa}$. Earth Planet. Sci. Lett. 464, 135-141 (2017).

36. Akahama, Y. \& Kawamura, H. High-pressure Raman spectroscopy of diamond anvils to $250 \mathrm{GPa}$ : method for pressure determination in the multimegabar pressure range. J. Appl. Phys. 96, 3748-3751 (2004).

37. Andrault, D. et al. Solidus and liquidus profiles of chondritic mantle: implication for melting of the Earth across its history. Earth Planet. Sci. Lett. 304, 251-259 (2011).

38. Fukai, Y. Some properties of the Fe-H system at high pressures and temperatures, and their implications for the Earth's core. In High-Pressure Research: Applications to Earth and Planetary Sciences Vol. 67 (eds. Syono, Y. \& Manghnani, M. H.) 373-385 (TERRAPUB, 1992).

39. Caracas, R. The influence of hydrogen on the seismic properties of solid iron. Geophys. Res. Lett. 42, 3780-3785 (2015).
40. Machida, A. et al. Site occupancy of interstitial deuterium atoms in facecentred cubic iron. Nat. Commun. 5, 5063 (2014).

41. Ikuta, D. et al. Interstitial hydrogen atoms in face-centered cubic iron in the Earth's core. Sci. Rep. 9, 7108 (2019).

42. Dewaele, A. et al. Quasihydrostatic equation of state of iron above $2 \mathrm{Mbar}$. Phys. Rev. Lett. 97, 215504 (2006).

43. Tsujino, N. et al. Equation of state of $\gamma$-Fe: reference density for planetary cores. Earth Planet. Sci. Lett. 375, 244-253 (2013).

44. Thompson, E. C., Campbell, A. J. \& Tsuchiya, J. Elasticity of $\varepsilon-\mathrm{FeOOH}$ seismic implications for Earth's lower mantle. J. Geophys. Res. Solid Earth 122, 5038-5047 (2017)

45. Yurimoto, H., Nagashima, K. \& Kunihiro, T. High precision isotope microimaging of materials. Appl. Surf. Sci. 203-204, 793-797 (2003).

46. Greenwood, J. P. et al. Hydrogen isotope ratios in lunar rocks indicate delivery of cometary water to the Moon. Nat. Geosci. 4, 79-82 (2011).

47. Sakamoto, N. et al. Remnants of the early solar system water enriched in heavy oxygen isotopes. Science 317, 231-233 (2007).

48. Yamamoto, K., Sakamoto, N. \& Yurimoto, H. Analysis of the noise properties of a solid-state SCAPS ion imager and development of software noise reduction. Surf. Interface Anal. 42, 1603-1605 (2010).

49. Yoshimura, S. Diffusive fractionation of $\mathrm{H}_{2} \mathrm{O}$ and $\mathrm{CO}_{2}$ during magma degassing. Chem. Geol. 411, 172-181 (2015).

50. Fukai, Y. The Metal-Hydrogen System. Vol. 21 (Springer-Verlag, 2005)

51. Righter, K. \& Drake, M. J. Effect of water on metal-silicate partitioning of siderophile elements: a high pressure and temperature terrestrial magma ocean and core formation. Earth Planet. Sci. Lett. 171, 383-399 (1999).

52. Clesi, V. et al. Effect of $\mathrm{H}_{2} \mathrm{O}$ on metal-silicate partitioning of $\mathrm{Ni}, \mathrm{Co}, \mathrm{V}, \mathrm{Cr}$ $\mathrm{Mn}$ and Fe: implications for the oxidation state of the Earth and Mars. Geochim. Cosmochim. Acta 192, 97-121 (2016).

53. Takahashi, E. Melting of a dry peridotite KLB-1 up to $14 \mathrm{GPa}$ implications on the origin of peridotitic upper mantle. J. Geophys. Res. 91, 9367-9382 (1986).

54. McDonough, W. F. Compositional model for the Earth's core. In Treatise on Geochemistry 2nd edn, Vol. 3 (eds. Holland, H. D. \& Turekian, K. K.) 559-577 (Elsevier, 2014).

55. Badro, J., Cote, A. S. \& Brodholt, J. P. A seismologically consistent compositional model of Earth's core. Proc. Natl Acad. Sci. USA 111, $7542-7545$ (2014)

56. Hirose, K. et al. Crystallization of silicon dioxide and compositional evolution of the Earth's core. Nature 543, 99-102 (2017).

57. Siebert, J., Badro, J., Antonangeli, D. \& Ryerson, F. J. Terrestrial accretion under oxidizing conditions. Science 339, 1194-1197 (2013).

58. Dauphas, N. The isotopic nature of the Earth's accreting material through time. Nature 541, 521-524 (2017).

59. McDonough, W. F. \& Sun, S. The composition of the Earth. Chem. Geol. 120, 223-253 (1995)

60. Rubie, D. C. et al. Heterogeneous accretion, composition and core-mantle differentiation of the Earth. Earth Planet. Sci. Lett. 301, 31-42 (2011).

61. Deguen, R., Olson, P. \& Cardin, P. Experiments on turbulent metal-silicate mixing in a magma ocean. Earth Planet. Sci. Lett. 310, 303-313 (2011).

62. Turcotte, D. \& Schubert, G. Geodynamics 3rd edn (Cambridge University Press, 2014)

63. Mann, U., Frost, D. J. \& Rubie, D. C. Evidence for high-pressure core-mantle differentiation from the metal-silicate partitioning of lithophile and weaklysiderophile elements. Geochim. Cosmochim. Acta 73, 7360-7386 (2009).

64. Peslier, A. H., Schönbächler, M., Busemann, H. \& Karato, S. I. Water in the Earth's interior: distribution and origin. Space Sci. Rev. 212, 1-68 (2017).

65. Palme, H. \& O'Neill, H. S. C. Cosmochemical estimates of mantle composition. In Treatise on Geochemistry 2nd edn, Vol. 3 (eds. Holland, H. D. \& Turekian, K. K.) 1-39 (Elsevier, 2014).

\section{Acknowledgements}

We thank N. Hirao and S. Kawaguchi for their assistance in experiments at BL10XU, SPring-8 (proposal no. 2018A0072 and 2018B0072). S. Yoshimura is acknowledged for preparing standards for SIMS analyses. K. Yonemitsu supports FIB analyses. We also thank M. Takei and M. Kusuzaki for sample holder development. Comments from M. Bouhifd and two anonymous referees were helpful to improve the manuscript. This work was supported by JSPS Kakenhi to K.H. and H.Y. and fellowship to S.T., and by the "Imaging Platform" program by MEXT.

\section{Author contributions}

S.T. designed and led the project together with K.H. and H.Y. High-pressure experiments and SIMS analyses were performed by Y.O. and N.S., respectively. S.T., K.H., and S.Y. performed computational simulations. S.T, K.H., and J.H. wrote the manuscript, and all authors commented on it

\section{Competing interests}

The authors declare no competing interests. 


\section{Additional information}

Supplementary information The online version contains supplementary material available at https://doi.org/10.1038/s41467-021-22035-0.

Correspondence and requests for materials should be addressed to S.T. or K.H.

Peer review information Nature Communications thanks Jie Li and the other, anonymous reviewers for their contribution to the peer review of this work.

Reprints and permission information is available at http://www.nature.com/reprints

Publisher's note Springer Nature remains neutral with regard to jurisdictional claims in published maps and institutional affiliations. (c) (1) Open Access This article is licensed under a Creative Commons Attribution 4.0 International License, which permits use, sharing, adaptation, distribution and reproduction in any medium or format, as long as you give appropriate credit to the original author(s) and the source, provide a link to the Creative Commons license, and indicate if changes were made. The images or other third party material in this article are included in the article's Creative Commons license, unless indicated otherwise in a credit line to the material. If material is not included in the article's Creative Commons license and your intended use is not permitted by statutory regulation or exceeds the permitted use, you will need to obtain permission directly from the copyright holder. To view a copy of this license, visit http://creativecommons.org/ licenses/by/4.0/.

(C) The Author(s) 2021 